\title{
Radiation-induced upregulation of telomerase activity escapes PI3-kinase inhibition in two malignant glioma cell lines
}

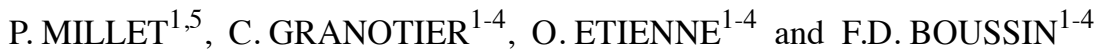 \\ ${ }^{1}$ CEA, DSV-IRCM-SCSR, Laboratory of Radiopathology, UMR 967, F-92260 Fontenay-aux-Roses; \\ ${ }^{2}$ INSERM, UMR 967, F-92260 Fontenay-aux-Roses; ${ }^{3}$ Univ Paris Diderot, Sorbonne Paris Cité, UMR 967, \\ F-92260 Fontenay-aux-Roses; ${ }^{4}$ Univ Paris-Sud, UMR 967, F-92260 Fontenay-aux-Roses, France
}

Received March 10, 2013; Accepted April 19, 2013

DOI: 10.3892/ijo.2013.1970

\begin{abstract}
Tumor relapse after radiotherapy is a great concern in the treatment of high-grade gliomas. Inhibition of the PI3-kinase/AKT pathway is known to radiosensitize cancer cells and to delay their DNA repair after irradiation. In this study, we show that the radiosensitization of CB193 and T98G, two high-grade glioma cell lines, by the PI3K inhibitor LY294002, correlates with the induction of G1 and G2/M arrest, but is inconsistently linked to a delayed DNA doublestrand break (DSBs) repair. The PI3K/AKT pathway has been shown to activate radioprotective factors such as telomerase, whose inhibition may contribute to the radiosensitization of cancer cells. However, we show that radiation upregulates telomerase activity in LY-294002-treated glioma cells as well as untreated controls, demonstrating a PI3K/AKT-independent pathway of telomerase activation. Our study suggests that radiosensitizing strategies based on PI3-kinase inhibition in high-grade gliomas may be optimized by additional treatments targeting either telomerase activity or telomere maintenance.
\end{abstract}

\section{Introduction}

Glioblastoma multiforme (GBM) is the most common and the most aggressive brain tumor with a median survival of only 15 months (1,2). Despite conjugated surgery, radiotherapy and chemotherapy most patients die within the first year of diagnosis $(3,4)$. The molecular mechanisms implicated in the resistance of glioblastoma to chemotherapies and radiotherapies overlap with those implicated in oncogenesis (5). Among those, the PI3K/AKT pathway which is implicated in

Correspondence to: Dr Pascal Millet, ${ }^{5}$ Present address: Aix-Marseille Univ, CNRS, NICN, UMR 7259, North Medical Faculty, CS 811, 51 Bd Pierre Dramard, 13344 Marseille Cedex 15, France

E-mail: pascal.millet@univ-amu.fr

Key words: telomerase, radiation, PI3-kinase, radiosensitization, glioma, glioblastoma regulation of cell proliferation, cell cycle, survival, apoptosis, migration and angiogenesis, is a major one (6-16).

The activation of the AKT pathway promotes the transition from anaplastic astrocytoma to glioblastoma (17), is correlated to histological malignant evolution and is a negative prognosis factor $(18,19)$. Moreover, the intrinsic radioresistance of glioblastoma is correlated with activation levels of AKT (15) and the activation of AKT confers them radioresistance (7). During carcinogenesis, the activation of the AKT pathway mainly occurs by the gain of activity of upstream activators such as EGFR (12,20-23), or by the loss of activity of an upstream inhibitor, PTEN (7,24,25). PTEN dephosphorylates PIP3 into PIP2 via its lipid-phosphatase activity and decreases the level of the phosphorylated active form of $\operatorname{AKT}(24,26)$.

During gliomagenesis, the AKT pathway is also frequently activated (27,28) and PTEN disrupted (29-31). Consequently the inhibition of AKT by either PTEN re-expression or PI3K inhibitors impairs DNA repair and radiosensitizes glioblastoma $(13,15,32,33)$.

Telomerase is a specific reverse transcriptase that elongates the telomeres, enables unlimited proliferation of cancer cells and is currently related to their radioresistance (34-36). Consequently telomerase inhibition shortens telomeres and radiosensitizes cells (37). Telomerase is reactivated in 80-100\% of glioblastomas (38) and its levels are correlated with the pathological grade and the prognosis of the tumor (38-42). This suggests that telomerase might also intervene in the radioresistance of glioblastomas by either triggering telomere maintenance and/or chromosome healing (43). Consequently telomere targeting or telomerase inhibition radiosensitizes glioblastoma cell lines (11,44-46). The evidenced importance of telomerase activity in the biology and the clinical outcomes of gliomas points out this enzyme as an appropriate therapeutic target for the radiosensitization of glioblastomas.

Interestingly, the telomerase activity is directly regulated by AKT either by phosphorylation of the hTERT subunit (47) or by both post-translational and transcriptional mechanisms $(48,49)$. Furthermore, ionizing radiation increases the telomerase activity in various cancer cell lines $(35,50-53)$ by a post-translational mechanism implicating PI3K/AKT pathway (54). But still, the upregulation of telomerase activity induced by ionizing radiation in glioblastoma cells (46) remains to be linked to PTEN/PI3-kinase/AKT pathway. 
As both PI3K/AKT and telomerase appear to be potential targets for cancer therapy and radio-sensitization of brain cancers $(5,11,15,16,43,45,55-57)$, we decided to study the links between telomerase activity and AKT pathway in human glioblastomas in order to challenge the idea of a 'killing two birds with one stone' radio-sensitizing strategy.

Therefore, we evaluated the effects of a specific PI3K inhibitor (Ly-294002) (58) in the radioresponse of two telomerase positive high-grade glioma cell lines: CB193 (grade III WHO) a PTEN null one $(59,60)$ and a T98G (grade IV WHO) a PTEN harbouring one $(61,62)$.

\section{Materials and methods}

Cell culture. Human malignant glioma cell lines CB193 (astrocytoma, grade III) (59) and T98G (glioblastoma multiforme, grade IV) $(61,62)$ were kindly provided by Dr G. Gras (CEA, France). Cultures $\left(5 \times 10^{5}\right.$ cells/flask) were maintained in DMEM medium (Life Technologies, Grand Island, NY, USA) supplemented with $10 \%$ fetal bovine serum (Life Technologies), 2 mM glutamine (Sigma, St. Louis, MO, USA) and antibiotics (penicillin, $100 \mathrm{U} / \mathrm{ml}$ and streptomycin, $100 \mu \mathrm{g}$ / $\mathrm{ml}$; Sigma), in a $5 \% \mathrm{CO}_{2}$ atmosphere at $37^{\circ} \mathrm{C}$. Cells were collected by trypsin treatment and counted using trypan blue. Ly-294002 (Ly, Biomol) a potent inhibitor of phosphoinositol 3-kinase (PI3K) was dissolved in DMSO (Sigma) and stored at $-20^{\circ} \mathrm{C}$. This solution was diluted in culture medium $24 \mathrm{~h}$ after seeding to treat cultures during exponential asynchronous growth to a final concentration of $50 \mu \mathrm{M}$. Control cells were treated with the corresponding concentration of DMSO $(0.2 \%)$. Cells were $\gamma$-irradiated during exponential asynchronous growth at 2 or 5 Gy (IBL637, CisBio International). When cells were treated with PI3K inhibitor and $\gamma$-irradiated, $50 \mu \mathrm{M}$ of Ly-294002 was added to culture medium $1 \mathrm{~h}$ before irradiation.

Western blot analysis. Cells were lysed in ice-cold CHAPS lysis buffer. The protein concentration was estimated in the supernatant using the Bio-Rad protein assay according to the manufacturer's protocol. Lysates (30 $\mu \mathrm{g}$ for CB193 and $25 \mu \mathrm{g}$ for T98G) were separated by SDS-PAGE under reducing conditions before transfer onto nitrocellulose membranes (Life Technologies). Equal protein loading was confirmed by Ponceau staining. Blots were blocked in TBS buffer containing 5\% non-fat dried milk for $1 \mathrm{~h}$ at room temperature. The membranes were incubated for $1 \mathrm{~h}$ at room temperature or overnight at $4^{\circ} \mathrm{C}$ with the primary antibodies: rabbit anti$\gamma$-AKT Ser473 clone 193H12 (Cell Signaling Technology, Danvers, MA, USA), mouse anti-AKT (Cell Signaling), mouse anti-PTEN clone A2B1 (Becton-Dickinson, Franklin Lakes, NJ, USA) or mouse anti- $\beta$-actin (Sigma). Membranes were then washed and incubated with the secondary antibody (GE Healthcare, Velizy, France) for $1 \mathrm{~h}$ at room temperature before washes. Detection of antibody binding was performed by enhanced chemiluminescence according to the manufacturer's instructions (ECL Super Signal Western blotting detection kit, GE Healthcare).

Colony-forming unit (CFU) assay. For CFU assay, CB193 and T98G $\left(5 \times 10^{5}\right.$ cells/T25 flask) were cultured for $24 \mathrm{~h}$ at $37^{\circ} \mathrm{C}$ then treated with Ly-294002 or the corresponding concentration of DMSO (Sigma) and $\gamma$-irradiated as described above. Cultures were incubated at $37^{\circ} \mathrm{C}$ for another $24 \mathrm{~h}$. Cultures were then trypsinized and counted using Trypan blue. A fixed number of experimentally determined living cells (600 cells for T98G, 800 cells for CB193) were re-seeded in 6-well plates in fresh culture medium without PI3K-inhibitor and CFU ( $>50$ cells) were stained with methylene blue and counted after 14-20 days in culture.

Apoptosis assay. Apoptotic cells were quantified by the detection of cleaved capsase-3 by immunostaining. Briefly, cells were grown in 8-well Lab-Tek chamber slides and fixed in $4 \%$ paraformaldehyde and permeabilized using $0.1 \%$ Triton $\mathrm{X}-100$ and $0.1 \%$ sodium citrate. After a blocking step $(7.5 \%$ goat serum and $7.5 \%$ fetal calf serum in PBS, $1 \mathrm{~h}$ at room temperature), cells were incubated with a 1:200 dilution of rabbit antibody specific for the cleaved form of caspase-3 (cleaved caspase-3 (Asp175) antibody, Cell Signaling) for $1 \mathrm{~h}$ at room temperature. After washings, cells were incubated with 1:125 dilution of Texas-Red-conjugated anti-rabbit IgG for $50 \mathrm{~min}$ at room temperature and then counterstained with DAPI before observation under a fluorescence microscope (Olympus BX51).

Cell cycle analysis. Cells were collected by trypsin, washed with PBS, fixed in $80 \%$ ethanol and kept at $-20^{\circ} \mathrm{C}$ for $\geq 24 \mathrm{~h}$. They were then washed in PBS and resuspended in $50 \mu \mathrm{g} / \mathrm{ml}$ propidium iodide and RNase-DNase free $(10 \mu \mathrm{g} / \mathrm{ml})$. The cell suspension was incubated for $30 \mathrm{~min}$ at room temperature and cell cycle distribution was determined by flow cytometry (FACSCalibur, BD, Franklin Lakes, NJ, USA), with CellQuest software analysis and quantification using Win-MDI software.

Immunostaining. Cells were grown in 8-well Lab-Tek chamber slides and fixed in $4 \%$ paraformaldehyde and permeabilized using $0.1 \%$ Triton $\mathrm{X}-100$ and $0.1 \%$ sodium citrate. After a blocking step $(7.5 \%$ goat serum and $7.5 \%$ fetal calf serum in PBS, $1 \mathrm{~h}$ at room temperature), cells were incubated with the primary antibody: mouse anti- $\gamma$-H2AX clone JBW301 (Merck Millipore, MA, USA), diluted in blocking buffer (1:200) for $1 \mathrm{~h}$ at room temperature. Then, cells were washed and incubated with Alexa-594 anti-mouse antibody (Life Technologies) diluted in blocking buffer (1:400) for $50 \mathrm{~min}$ at room temperature. After washing, cells were then counterstained with DAPI before observation under a fluorescence microscope (Olympus BX51).

Telomerase activity assay. Telomerase activity was assessed with the TRAPeze ELISA Telomerase Detection kit (S7750, Merck Millipore) according to the manufacturer's instructions. Briefly, the cells were seeded $\left(2 \times 10^{6}\right.$ cells/T75 flask) for $24 \mathrm{~h}$ at $37^{\circ} \mathrm{C}$ then treated with Ly-294002 or the corresponding concentration of DMSO and $\gamma$-irradiated as described above. Cultures were transferred to an incubator at $37^{\circ} \mathrm{C}$ for another $24 \mathrm{~h}$. Then the cells were collected by trypsin treatment in cold PBS and counted in triplicate using trypan blue. Cells were lysed in ice-cold CHAPS lysis buffer. After incubation at $4^{\circ} \mathrm{C}$ for $30 \mathrm{~min}$ and a centrifugation at $16,000 \mathrm{~g}$ for $25 \mathrm{~min}$ at $4^{\circ} \mathrm{C}$, cell extracts were kept frozen at $-80^{\circ} \mathrm{C}$. Telomerase 
A

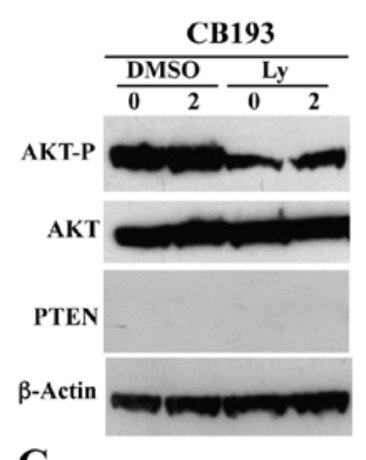

C

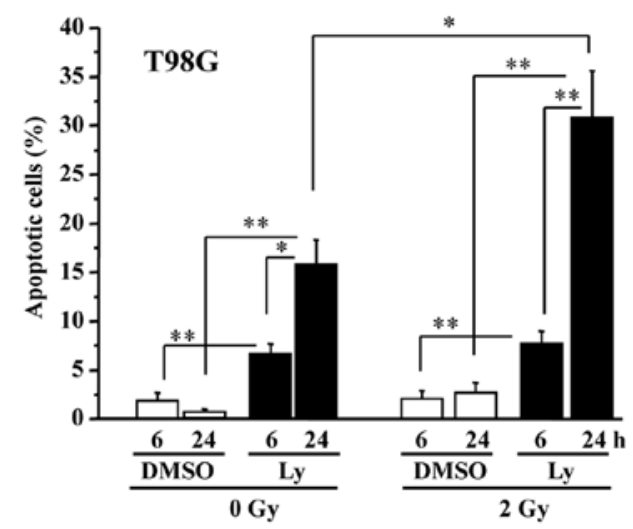

B

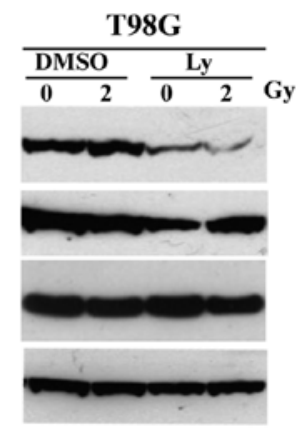

D
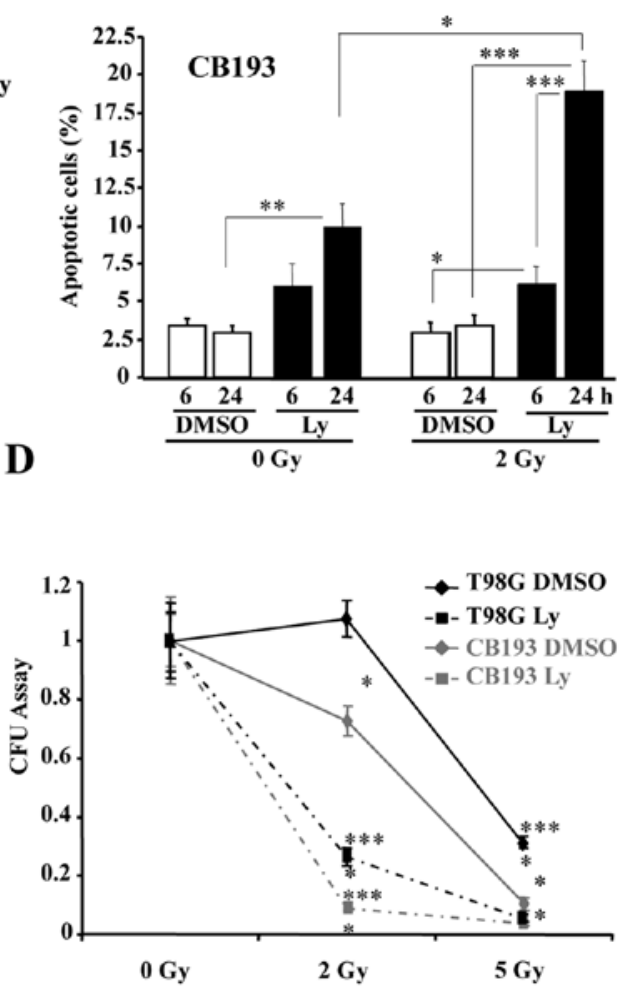

Figure 1. Ly-294002 radiosensitizes CB193 and T98G. (A) Western blot analysis of AKT, AKT-P (phosphorylated form of AKT), PTEN and $\beta$-actin, 24 h after irradiation when CB193 and T98G were pre-treated with Ly-294002 or DMSO. (B and C) Cleaved caspase-3 detection by immunofluorescence 6 and 24 h after irradiation. Histograms showing the percentage of cleaved caspase-3-positive cells \pm standard deviation with the respect to the total DAPI stained CB193 (B) and T98G (C) populations. Results are representative of two independent experiments ( $>400$ cells analyzed per condition). (D) Colony forming unit (CFU) assay on CB193 and T98G treated with PI3K inhibitor (50 $\mu$ M Ly294002) and irradiated with 2 or 5 Gy. A fixed number of living cells were seeded in plates with fresh culture medium without PI3K inhibitor $24 \mathrm{~h}$ after irradiation and colonies ( $>50$ cells) were counted 14-20 days later. Mean number of colony forming unit from triplicate cultures \pm standard deviation, are representative of two independent experiments. The curves were normalized to that of sham-irradiated control DMSO-treated cells. Statistics (t-test): ${ }^{*} \mathrm{P}<0.05 ;{ }^{* *} \mathrm{P}<0.01 ;{ }^{* * *} \mathrm{P}<0.001$.

activity was then measured on proteins corresponding to an experimentally fixed number of cells (234 cells CB193 and 166 cells for $\mathrm{T} 98 \mathrm{G}$ ) in a $50-\mu 1$ reaction mixture containing $10 \mu \mathrm{l}$ of 5X TRAP reaction mix and $2 \mathrm{U}$ of Taq DNA polymerase (GE Healthcare). The reaction mixture was incubated for $30 \mathrm{~min}$ at $30^{\circ} \mathrm{C}$. The extended products were amplified by a polymerase chain reaction (PCR, 32 cycles at $94^{\circ} \mathrm{C}$ for $30 \mathrm{sec}$ and at $59^{\circ} \mathrm{C}$ for $30 \mathrm{sec}$ ) on a PTC-200 thermocycler (MJ Research). The amplification products were immobilized onto streptavidin-coated microtitre plates and detected by an anti-DNP antibody conjugated to horseradish peroxidase (HRP). After addition of the peroxidase substrate (3,3', 5, 5 '-tetramethylbenzidine), the amount of TRAP products was determined by measuring the absorbance at 450 and $690 \mathrm{~nm}$. Telomerase activity was semi-quantified using an internal standard curve.

Statistical analysis. All statistical analyses were performed using the StatView software (Abcus Concepts) and Student's t-test was used to evaluate the statistical significance of mean values between conditions. In each figure error bars represent standard error of the mean and statistical significance levels are noted as follows: ${ }^{*} \mathrm{P}<0.05,{ }^{* *} \mathrm{P}<0.01,{ }^{* * *} \mathrm{P}<0.001$.

\section{Results}

Ly-294002 radiosensitizes glioma cell lines. As shown in Fig. 1A, treatment with $50 \mu \mathrm{M}$ Ly-294002 resulted in a significant dephosphorylation of AKT in both CB193 and T98G glioma cell lines, but 2-Gy radiation had no detectable effect on AKT phosphorylation. Consistent with the importance of AKT phosphorylation for cell survival, immuno-detection of cleaved-caspase-3 showed that apoptosis increased in Ly-294002-treated cultures (Fig. 1B and C). Moreover, 2-Gy radiation did not significantly induce apoptosis in DMSOtreated glioma cell lines, but nearly doubled apoptosis levels in Ly-294002-treated cells $24 \mathrm{~h}$ after irradiation (PI) (30.9 $\pm 4.6 \mathrm{vs}$ $15.7 \pm 2.6 \%$ in $\mathrm{T} 98 \mathrm{G}$ cells and $18.9 \pm 2.0$ vs. $9.2 \pm 1.5 \%$ in CB193 cells), showing that Ly-294002 radiosensitizes glioma cell lines.

This was further confirmed by determining the capacity of irradiated glioma cells to form colonies after a $24 \mathrm{~h}$ treatment with $50 \mu \mathrm{M}$ Ly-294002 or with DMSO in a CFU assay (Fig. 1D). Ly-294002 strongly decreased the clonogenicity of 2-Gy-irradiated CB193 and T98G cells, whereas 2-Gy radiation alone had no (T98G) or only a moderate (CB193) effect on DMSO-treated glioma cell clonogenicity. Radiosensitization 

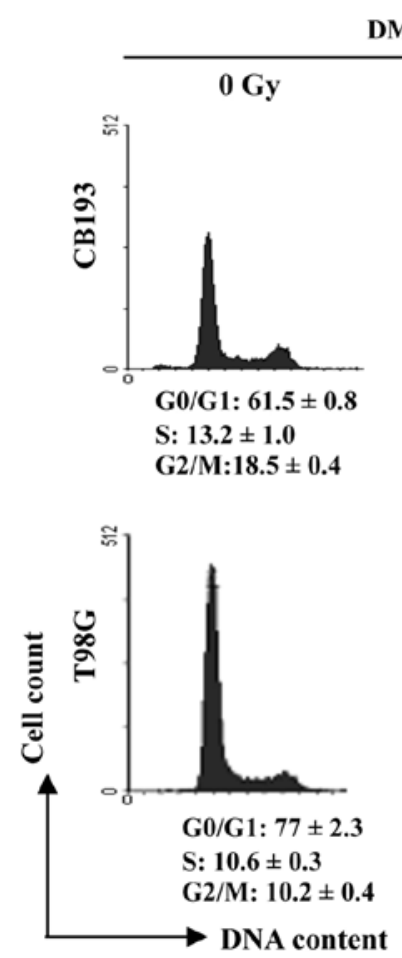

DMSO
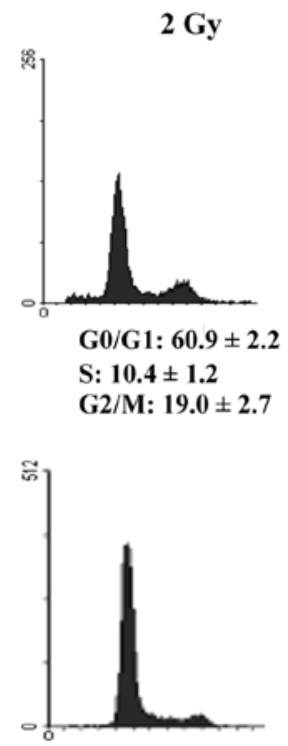

G0/G1: $77.3 \pm 3.1$

S: $10.6 \pm 1.9$

G2/M: $11.1 \pm 2.1$

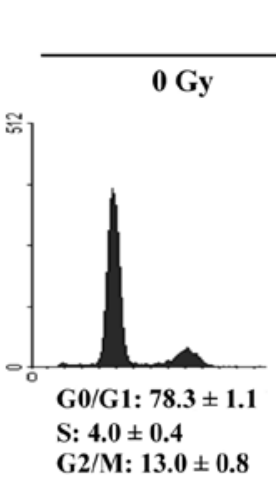

Ly
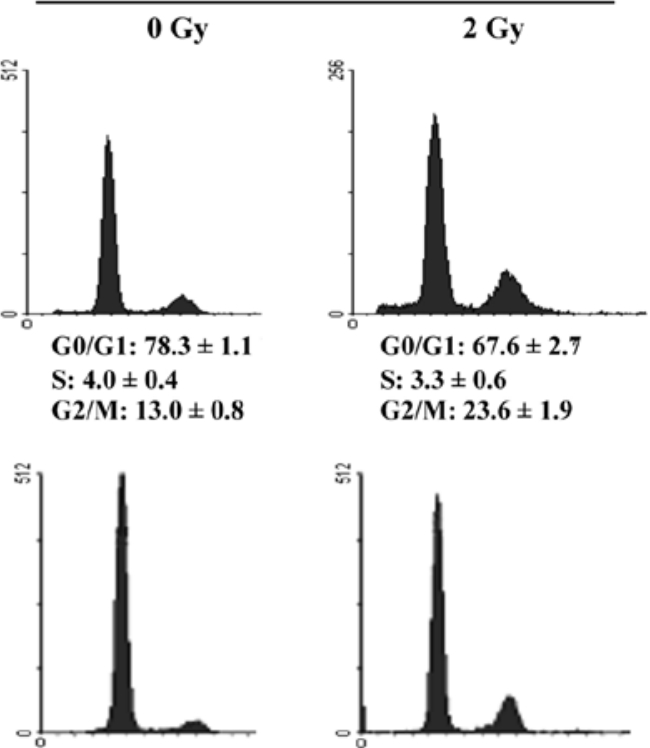

G0/G1: $87.9 \pm 0.7$

S: $3.3 \pm 0.2$

G2/M: $6.9 \pm 0.4$

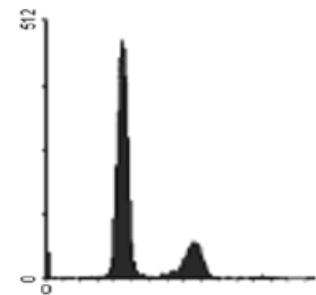

G0/G1: $74.5 \pm 0.9$

S: $4.2 \pm 0.5$

G2/M: $19.2 \pm 0.4$

Figure 2. Ly-294002 induces a G2/M cell cycle arrest in irradiated T98G and CB193. Histograms of the 24-h cell cycle of surviving CB193 and T98G treated with $50 \mu \mathrm{M} \mathrm{Ly}$ and irradiated at $2 \mathrm{~Gy}$ and controls. The cells were stained with propidium-iodide and analysed by FACS. The percentages of cells in different phases of the cell cycle from triplicate cultures are expressed with respect to the total number of viable cells (corresponding to an analysis of $10^{5}$ cells) and are representative of two independent experiments performed $24 \mathrm{~h}$ after irradiation.

by Ly-294002 was also observed in T98G cells after 5 Gy, a dose that was sufficient to abolish CB193 clonogenicity.

Radiation-induced G2/M arrest in Ly-294002-treated glioma cells. The PI3K/AKT pathway plays multiple roles in cell cycle progression (63). Measuring DNA content by flow cytometry showed that Ly-294002 induced a G1 arrest in glioma cells, consistently with the requirement of PI3K/AKT pathway for $\mathrm{G} 1 / \mathrm{S}$ transition that has been previously reported in many cell types (63).

Consistent with the little or absent effect of 2-Gy radiation on glioma cell viability, as shown above (Fig. 1D), the cell cycle progression was not altered in irradiated DMSO-treated cells (Fig. 2). Besides, a significant decrease in $\mathrm{S}$ phase cells showed that Ly-294002 blocked G1/S transition in irradiated cultures similarly to the non-irradiated ones. Moreover, irradiation induced an increase in G2/M cells in Ly-294002treated cultures, which was more pronounced in T98G than in CB193 cells. These data revealed that, besides its effects at the G1/S transition, Ly-294002 also inhibited cell cycle progression at the $\mathrm{G} 2 / \mathrm{M}$ transition after radiation-induced DNA damage.

Ly-294002 delays DNA double strand break (DSB) repair. DNA damage and repair can be evaluated by quantifying $\gamma$-H2AX nuclear foci $(64,65)$. H2AX is a member of the nucleosome core histone $\mathrm{H} 2 \mathrm{~A}$ family, which is recruited and phosphorylated on serine 139 in chromatin surrounding the site of double strand breaks (DSBs) by kinases of the PI-3K family, ATM, DNA-PKcs or ATR $(66,67)$. In both CB193 and T98G cells, 2-Gy irradiation induced a significant increase in $\gamma-\mathrm{H} 2 \mathrm{AX}$ foci at $1 \mathrm{~h} \mathrm{PI}$, which returned to basal levels at $6 \mathrm{~h}$ PI, revealing no difference in the kinetics of DNA repair between the two glioma cell lines. Ly-294002 did not modify the number of $\gamma-\mathrm{H} 2 \mathrm{AX}$ foci at $1 \mathrm{~h}$ PI in irradiated cells (Fig. 3). This confirms that PI3K inhibition does not prevent DSB signaling at the concentration we used in agreement with previous studies $(13,68)$. By contrast, Ly-294002 inhibited the decrease in $\gamma$-H2AX foci in irradiated T98G cells at 6 and $24 \mathrm{~h}$ $\mathrm{PI}$, suggesting that PI3K inhibition suppressed DSB repair. Ly-294002 had smaller effects on CB193 since the number of foci was only slightly increased at 6 h PI in Ly-294002-treated cells compared with DMSO treated controls and recovered its basal level at $24 \mathrm{~h}$ PI. Altogether these data evidenced difference in the effects of Ly-294002 on DNA repair between the two cell lines. As we have shown above, the compound had similar effects on apoptosis induction and clonogenicity of the two glioma stem cells after irradiation, thus our data suggest that the radiosensitization by Ly-294002 is not strictly related to its effects on DNA repair.

Ly-294002 does not prevent radiation-induced upregulation of telomerase activity. PI3K inhibition induced by Ly-294002 decreases the telomerase activity (Fig. 4) and dephosphorylates AKT in both sham-irradiated CB193 and T98G, suggesting that telomerase activity could be regulated by PI3K and AKT phosphorylation in glioblastomas, as in many cell types $(47,49)$. Therefore, PI3K/AKT seems to regulate at least partly basal telomerase activity in our model.

We also found that radiation significantly increased telomerase activity in both CB193 and T98G at 24 h PI (Fig. 4). 
A

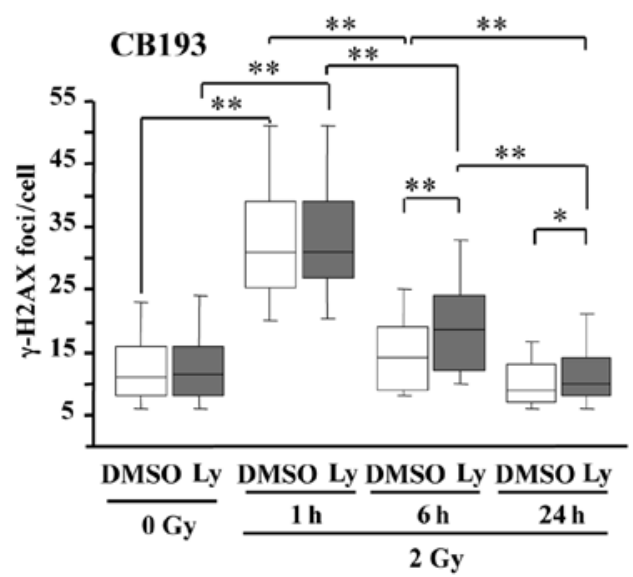

B

T98G

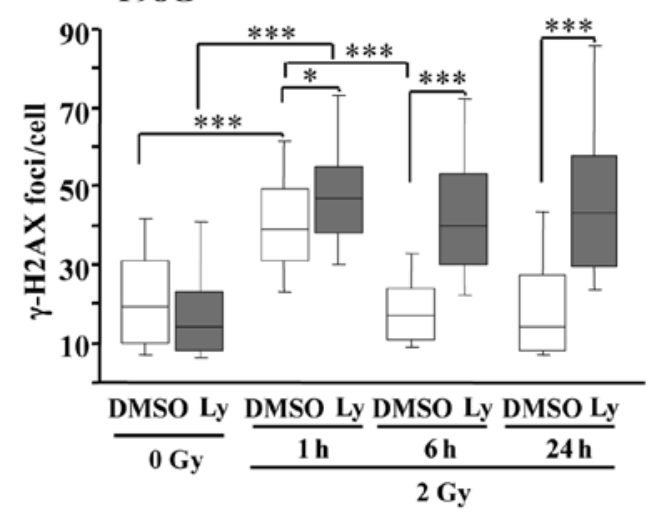

Figure 3. Ly-294002 delays diversely the DNA repair in T98G and CB193. Box graphs showing the distribution of $\gamma$-H2AX foci per cell in CB193 (A) and in T98G (B) cells 1, 6 and $24 \mathrm{~h}$ after irradiation (200-400 nuclei analyzed per condition). Boxes include $50 \%$ of the values centered on the median (the horizontal line through the box). The vertical lines begin at the 10th percentile and end at the 90th percentile. Results are representative of two independent experiments. More than 200 nuclei per condition in at least three different fields were counted. Statistics (t-test): ${ }^{*} \mathrm{P}<0.05 ;{ }^{* *} \mathrm{P}<0.01 ;{ }^{* * *} \mathrm{P}<0.001$.

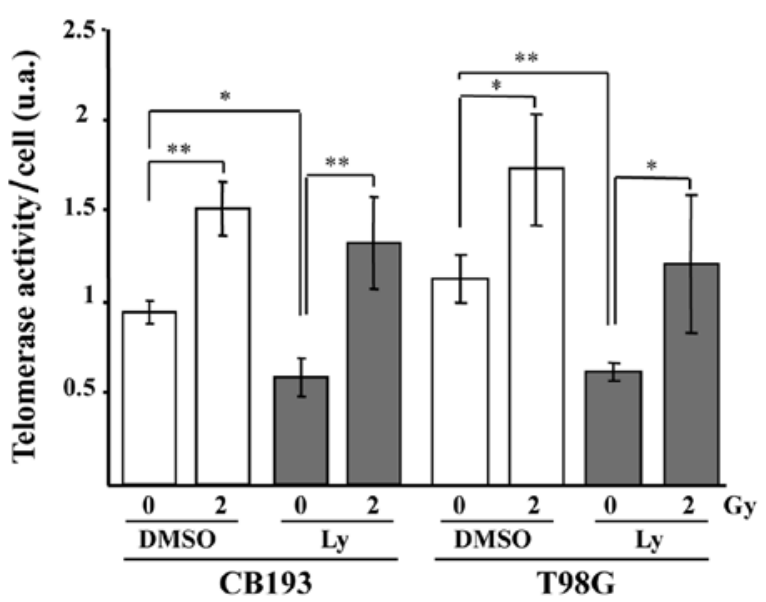

Figure 4. Influence of Ly-294002 treatment on telomerase activity. TRAP assay was performed on proteins corresponding to a fixed number of cells $24 \mathrm{~h}$ after irradiation. Cell related telomerase activity from duplicate \pm standard deviation is representative of two and four independent experiments for CB193 and T98G, respectively. Statistics (t-test): ${ }^{*} \mathrm{P}<0.05 ;{ }^{* *} \mathrm{P}<0.01$; ${ }^{* * *} \mathrm{P}<0.001$.

However, whereas Ly-294002 significantly decreased telomerase activity in unirradiated glioma cells, it failed to prevent the radiation-induced increase in telomerase activity in irradiated cells, ruling out a role of the PI3K/AKT pathway in the radiation-induced upregulation of telomerase activity in our model.

\section{Discussion}

The PI3-kinase/AKT pathway is more and more regarded as an interesting therapeutic target for the radiosensitization of glioblastoma, but the mechanisms of radiosensitization resulting from the inhibition of the PI3K/AKT pathway remain still unclear. Its inhibition has been reported to impair DNA repair in glioblastoma cells following ionizing radiation, thereby blocking cell cycle progression and cell death (13). In this study, we have shown that the radiosensitization of two glioma cell lines by the PI3K inhibitor, Ly-294002, correlated with the induction of G1 and G2/M arrests, but was inconsistently linked to a delayed DSBs repair. The PI3K/AKT pathway has been also shown to activate radioprotective factors such as telomerase, which inhibition may contribute to radiosensitization (11,44-46). However, we have shown that radiation upregulated telomerase activity in Ly-294002-treated glioma cells as well as in untreated controls, regardless of their PTEN status, evidencing a PI3K/AKT independent pathway of telomerase activation. High-grade gliomas are known for their inter- and intra-patient heterogeneity. They express diversely telomerase activity and telomerase sub-units, but this expression is strongly correlated to their progression in malignancy and a poor clinical outcome $(38,39,42,69-71)$. Our study tends to indicate that the strategy of radiosensitization of high-grade gliomas should combine different approaches and should be adapted to the individual characteristics of the tumor especially regarding their telomerase status.

Numerous previous reports have shown that inhibition of the PI3K/AKT pathways radiosensitize gliomas $(13,15,32,33)$, consistently with the activation of PI3K/AKT conferring radioresistance (7). Ionizing radiation has been shown to increase Akt phosphorylation in various cell lines including gliomas $(32,72)$. However, we did not find any radiationincrease of AKT phosphorylation in our two glioma cells, consistently with the study by Li et al (32) showing that AKT phosphorylation occurred only in a subset of glioblastoma cells.

Ly-294002 induced a G1 arrest in both CB193 and T98G cells in accordance with the importance of the PI3K/AKT signaling for G1/S transition (73-75). Moreover, as previously reported in other cell lines (76,77), inhibition of the PI3K/ AKT pathway resulted in an accumulation in $\mathrm{G} 2 / \mathrm{M}$ phase, but only after irradiation. Inhibition of the PI3K pathway has been shown to impair DNA repair after ionizing radiation, suggesting that the blocking at the G2/M transition and subse- 
quent cell death may result from an inhibition of DSB repair $(13,78)$. However, this is not fully sustained by our present study showing that the $\mathrm{G} 2 / \mathrm{M}$ arrest was correlated with a delay in DSBs repair only in T98G but not in CB193 cells, after the treatment with Ly-294002. Activation of AKT has been also shown to promote G2/M transition through the activation of downstream molecules such as cyclin B associated kinase, NF-Y, Chk1 and FOXO3A (79-81). Our data suggest that beside possible inhibition of DNA repair depending on the cellular context, Ly-294002 inhibits the signaling pathway required to pass the $\mathrm{G} 2 / \mathrm{M}$ checkpoint independently of DNA repair completion in irradiated cells.

Irradiation has been shown to upregulate telomerase activity in various cell lines $(35,50-53)$ including a glioblastoma cell line (46). AKT is able to phosphorylate hTERT, the catalytic subunit of telomerase and activate telomerase activity (47). Recently, AKT has been also shown to facilitate nuclear import of hTERT (82). Moreover, ionizing radiation has been reported to upregulate telomerase activity in cancer cell lines by post-translational mechanism via the PI3K/AKT pathway (54). While Ly-294002 decreased telomerase activity in unirradiated CB193 and T98G cells, concomitantly with AKT dephosphorylation and G1 arrest, we have shown that it did not prevent the radiation-induced increase of telomerase activity, which was not correlated with an increase of AKT phosphorylation in these cell lines. These results rule out a predominant role of the PI3K/AKT pathway in the radiationinduced upregulation of telomerase activity in our glioma cells lines suggesting that an alternative pathway is involved which remains to be determined. Such AKT/PKB independent upregulation of telomerase activity after irradiation have been already observed in other cell lines (83) but related to delayed DSB repair. Complementary studies of DSB repair-related molecules are needed in our model.

Telomerase is thought to increase the radiation resistance of cancer cells by either protecting telomeres from fusion or by its anti-apoptotic functions or by promoting DNA repair through its actions on the chromatin structure (11,34-36,8487). A telomerase antagonist, imetelstat in combination with radiation and temozolomide had a dramatic effect on cell survival of primary human glioblastoma tumor-initiating cells (45). Telomere targeting with a G-quadruplex ligand, has been recently reported to enhance radiation-induced killing of human glioblastoma cells (44).

The personalization of glioblastoma medicine around telomere profiling in radiation therapy is already under study (88), and could be extended to telomerase activity. Our results showing that telomerase upregulation was not abolished by the PI3K/AKT pathway inhibition, suggests that personalized combined therapies associating PI3K and telomerase inhibitors or telomere G-quadruplex ligands should be considered to improve the radiosensitization in telomerase expressing high-grade gliomas.

\section{References}

1. Stupp R, Mason WP, van den Bent MJ, et al: Radiotherapy plus concomitant and adjuvant temozolomide for glioblastoma. N Engl J Med 352: 987-996, 2005.

2. Wen PY and Kesari S: Malignant gliomas in adults. N Engl J Med 359: 492-507, 2008.
3. Stupp R, Hegi ME, Mason WP, et al: Effects of radiotherapy with concomitant and adjuvant temozolomide versus radiotherapy alone on survival in glioblastoma in a randomised phase III study: 5-year analysis of the EORTC-NCIC trial. Lancet Oncol 10: 459-466, 2009.

4. Koukourakis GV,Kouloulias V,Zacharias G, et al: Temozolomide with radiation therapy in high grade brain gliomas: pharmaceuticals considerations and efficacy; a review article. Molecules 14: 1561-1577, 2009.

5. Kondo Y, Hollingsworth EF and Kondo S: Molecular targeting for malignant gliomas (Review). Int J Oncol 24: 1101-1109, 2004

6. Tanaka H, Yoshida M, Tanimura $\mathrm{H}$, et al: The selective class I PI3K inhibitor CH5132799 targets human cancers harboring oncogenic PIK3CA mutations. Clin Cancer Res 17: 3272-3281, 2011.

7. Jiang Z, Pore N, Cerniglia GJ, et al: Phosphatase and tensin homologue deficiency in glioblastoma confers resistance to radiation and temozolomide that is reversed by the protease inhibitor nelfinavir. Cancer Res 67: 4467-4473, 2007.

8. Mason WP, Belanger K, Nicholas G, et al: A phase II study of the Ras-MAPK signaling pathway inhibitor TLN-4601 in patients with glioblastoma at first progression. J Neurooncol 107: 343-349, 2011.

9. Fass1 A, Tagscherer KE, Richter J, et al: Notch1 signaling promotes survival of glioblastoma cells via EGFR-mediated induction of anti-apoptotic Mcl-1. Oncogene 31: 4698-4708, 2012.

10. Stockhausen MT, Broholm H, Villingshoj M, et al: Maintenance of EGFR and EGFRvIII expressions in an in vivo and in vitro model of human glioblastoma multiforme. Exp Cell Res 317: 1513-1526, 2011.

11. Ji XM, Xie $\mathrm{CH}$, Fang $\mathrm{MH}$, et al: Efficient inhibition of human telomerase activity by antisense oligonucleotides sensitizes cancer cells to radiotherapy. Acta Pharmacol Sin 27: 1185-1191, 2006.

12. Chakravarti A, Zhai G, Suzuki Y, et al: The prognostic significance of phosphatidylinositol 3-kinase pathway activation in human gliomas. J Clin Oncol 22: 1926-1933, 2004.

13. Kao GD, Jiang Z, Fernandes AM, Gupta AK and Maity A: Inhibition of phosphatidylinositol-3-OH kinase/Akt signaling impairs DNA repair in glioblastoma cells following ionizing radiation. J Biol Chem 282: 21206-21212, 2007.

14. Gallia GL, Tyler BM, Hann CL, et al: Inhibition of Akt inhibits growth of glioblastoma and glioblastoma stem-like cells. Mol Cancer Ther 8: 386-393, 2009.

15. Chautard E, Loubeau G, Tchirkov A, et al: Akt signaling pathway: a target for radiosensitizing human malignant glioma. Neurooncology 12: 434-443, 2010.

16. Carnero A, Blanco-Aparicio C, Renner O, Link W and Leal JF: The PTEN/PI3K/AKT signalling pathway in cancer, therapeutic implications. Curr Cancer Drug Targets 8: 187-198, 2008.

17. Sonoda Y, Ozawa T, Aldape KD, Deen DF, Berger MS and Pieper RO: Akt pathway activation converts anaplastic astrocytoma to glioblastoma multiforme in a human astrocyte model of glioma. Cancer Res 61: 6674-6678, 2001.

18. Suzuki Y, Shirai K, Oka K, et al: Higher pAkt expression predicts a significant worse prognosis in glioblastomas. J Radiat Res 51: 343-348, 2010.

19. Ermoian RP, Furniss CS, Lamborn KR, et al: Dysregulation of PTEN and protein kinase B is associated with glioma histology and patient survival. Clin Cancer Res 8: 1100-1106, 2002.

20. Choe G, Horvath S, Cloughesy TF, et al: Analysis of the phosphatidylinositol 3'-kinase signaling pathway in glioblastoma patients in vivo. Cancer Res 63: 2742-2746, 2003.

21. Hayashi Y, Ueki K, Waha A, Wiestler OD, Louis DN and von Deimling A: Association of EGFR gene amplification and CDKN2 (p16/MTS1) gene deletion in glioblastoma multiforme. Brain Pathol 7: 871-875, 1997.

22. Sugawa N, Ekstrand AJ, James CD and Collins VP: Identical splicing of aberrant epidermal growth factor receptor transcripts from amplified rearranged genes in human glioblastomas. Proc Natl Acad Sci USA 87: 8602-8606, 1990.

23. Huang HS, Nagane M, Klingbeil CK, et al: The enhanced tumorigenic activity of a mutant epidermal growth factor receptor common in human cancers is mediated by threshold levels of constitutive tyrosine phosphorylation and unattenuated signaling. J Biol Chem 272: 2927-2935, 1997.

24. Haas-Kogan D, Shalev N, Wong M, Mills G, Yount G and Stokoe D: Protein kinase B (PKB/Akt) activity is elevated in glioblastoma cells due to mutation of the tumor suppressor PTEN/MMAC. Curr Biol 8: 1195-1198, 1998. 
25. Li J, Yen C, Liaw D, et al: PTEN, a putative protein tyrosine phosphatase gene mutated in human brain, breast and prostate cancer. Science 275: 1943-1947, 1997.

26. Myers MP, Pass I, Batty IH, et al: The lipid phosphatase activity of PTEN is critical for its tumor supressor function. Proc Natl Acad Sci USA 95: 13513-13518, 1998.

27. Holland EC, Celestino J, Dai C, Schaefer L, Sawaya RE and Fuller GN: Combined activation of Ras and Akt in neural progenitors induces glioblastoma formation in mice. Nat Genet 25: 55-57, 2000.

28. Rajasekhar VK, Viale A, Socci ND, Wiedmann M, Hu X and Holland EC: Oncogenic Ras and Akt signaling contribute to glioblastoma formation by differential recruitment of existing mRNAs to polysomes. Mol Cell 12: 889-901, 2003.

29. Smith JS, Tachibana I, Passe SM, et al: PTEN mutation, EGFR amplification and outcome in patients with anaplastic astrocytoma and glioblastoma multiforme. J Natl Cancer Inst 93: 1246-1256, 2001.

30. Knobbe CB, Merlo A and Reifenberger G: Pten signaling in gliomas. Neurooncology 4: 196-211, 2002.

31. Koul D: PTEN signaling pathways in glioblastoma. Cancer Biol Ther 7: 1321-1325, 2008 .

32. Li HF, Kim JS and Waldman T: Radiation-induced Akt activation modulates radioresistance in human glioblastoma cells Radiat Oncol 4: 43, 2009.

33. Nakamura JL, Karlsson A, Arvold ND, et al: PKB/Akt mediates radiosensitization by the signaling inhibitor LY294002 in human malignant gliomas. J Neurooncol 71: 215-222, 2005.

34. Turriziani M, Di Giacomo AM, Cardillo A, et al: Residual telomerase activity: a marker of cell survival after exposure to gamma radiation in vitro. Anticancer Res 23: 4561-4569, 2003.

35. Wang X, Liu Y, Chow LS, et al: Regulation of telomerase activity by gamma-radiation in nasopharyngeal carcinoma cells. Anticancer Res 20: 433-437, 2000.

36. Perez Mdel R, Dubner D, Michelin S, Leteurtre F, Carosella ED and Gisone PA: Radiation-induced upregulation of telomerase in KGla cells is influenced by dose-rate and radiation quality. Int J Radiat Biol 78: 1175-1183, 2002.

37. Wong KK, Chang S, Weiler SR, et al: Telomere dysfunction impairs DNA repair and enhances sensitivity to ionizing radiation. Nat Genet 26: 85-88, 2000.

38. Falchetti ML, Pallini R, D'Ambrosio E, et al: In situ detection of telomerase catalytic subunit mRNA in glioblastoma multiforme. Int J Cancer 88: 895-901, 2000.

39. Huang F, Kanno H, Yamamoto I, Lin Y and Kubota Y: Correlation of clinical features and telomerase activity in human gliomas. J Neurooncol 43: 137-142, 1999.

40. Harada K, Kurisu K, Tahara H, Tahara E and Ide T: Telomerase activity in primary and secondary glioblastomas multiforme as a novel molecular tumor marker. J Neurosurg 93: 618-625, 2000 .

41. Fukushima T, Yoshino A, Katayama Y, Watanabe T, Kusama K and Moro I: Prediction of clinical course of diffusely infiltrating astrocytomas from telomerase expression and quantitated activity level. Cancer Lett 187: 191-198, 2002.

42. Boldrini L, Pistolesi S, Gisfredi S, et al: Telomerase activity and hTERT mRNA expression in glial tumors. Int J Oncol 28 : 1555-1560, 2006.

43. Wesbuer S, Lanvers-Kaminsky C, Duran-Seuberth I, et al: Association of telomerase activity with radio- and chemosensitivity of neuroblastomas. Radiat Oncol 5: 66, 2010.

44. Merle P, Evrard B, Petitjean A, et al: Telomere targeting with a new G4 ligand enhances radiation-induced killing of human glioblastoma cells. Mol Cancer Ther 10: 1784-1795, 2011

45. Marian CO, Cho SK, McEllin BM, et al: The telomerase antagonist, imetelstat, efficiently targets glioblastoma tumor-initiating cells leading to decreased proliferation and tumor growth. Clin Cancer Res 16: 154-163, 2010.

46. Zhou FX, Liao ZK, Dai J, et al: Radiosensitization effect of zidovudine on human malignant glioma cells. Biochem Biophys Res Commun 354: 351-356, 2007.

47. Kang SS, Kwon T, Kwon DY and Do SI: Akt protein kinase enhances human telomerase activity through phosphorylation of telomerase reverse transcriptase subunit. J Biol Chem 274: 13085-13090, 1999.

48. Zhou C, Bae-Jump VL, Whang YE, Gehrig PA and Boggess JF: The PTEN tumor suppressor inhibits telomerase activity in endometrial cancer cells by decreasing hTERT mRNA levels. Gynecol Oncol 101: 305-310, 2006.
49. Uziel O, Fenig E, Nordenberg J, et al: Imatinib mesylate (Gleevec) downregulates telomerase activity and inhibits proliferation in telomerase-expressing cell lines. Br J Cancer 92: 1881-1891, 2005.

50. Leteurtre F, Li X, Gluckman E and Carosella ED: Telomerase activity during the cell cycle and in gamma-irradiated hematopoietic cells. Leukemia 11: 1681-1689, 1997.

51. Finnon P, Silver AR and Bouffler SD: Upregulation of telomerase activity by X-irradiation in mouse leukaemia cells is independent of Tert, Terc, Tnks and Myc transcription. Carcinogenesis 21: 573-578, 2000.

52. Hande MP, Balajee AS and Natarajan AT: Induction of telomerase activity by UV-irradiation in Chinese hamster cells. Oncogene 15: $1747-1752,1997$.

53. Hyeon Joo O, Hande MP, Lansdorp PM and Natarajan AT: Induction of telomerase activity and chromosome aberrations in human tumour cell lines following X-irradiation. Mutat Res 401: 121-131, 1998.

54. Ram R, Uziel O, Eldan O, et al: Ionizing radiation upregulates telomerase activity in cancer cell lines by post-translational mechanism via ras/phosphatidylinositol 3-kinase/Akt pathway. Clin Cancer Res 15: 914-923, 2009.

55. Lefranc F, Rynkowski M, DeWitte O and Kiss R: Present and potential future adjuvant issues in high-grade astrocytic glioma treatment. Adv Tech Stand Neurosurg 34: 3-35, 2009.

56. Cully M, You H, Levine AJ and Mak TW: Beyond PTEN mutations: the PI3K pathway as an integrator of multiple inputs during tumorigenesis. Nat Rev Cancer 6: 184-192, 2006.

57. Hennessy BT, Smith DL, Ram PT, Lu Y and Mills GB: Exploiting the PI3K/AKT pathway for cancer drug discovery. Nat Rev Drug Discov 4: 988-1004, 2005.

58. Vlahos CJ, Matter WF, Hui KY and Brown RF: A specific inhibitor of phosphatidylinositol 3-kinase, 2-(4-morpholinyl)-8phenyl-4H-1-benzopyran-4-one (LY294002). J Biol Chem 269: 5241-5248, 1994

59. Menet A, Speth C, Larcher C, et al: Epstein-Barr virus infection of human astrocyte cell lines. J Virol 73: 7722-7733, 1999.

60. Pennarun G, Granotier C, Gauthier LR, et al: Apoptosis related to telomere instability and cell cycle alterations in human glioma cells treated by new highly selective G-quadruplex ligands. Oncogene 24: 2917-2928, 2005.

61. Walker SM, Leslie NR, Perera NM, Batty IH and Downes CP The tumour-suppressor function of PTEN requires an $\mathrm{N}$-terminal lipid-binding motif. Biochem J 379: 301-307, 2004.

62. Sano T, Asai A, Mishima K, Fujimaki T and Kirino T: Telomerase activity in 144 brain tumours. Br J Cancer 77: 1633-1637, 1998.

63. Liang J and Slingerland JM: Multiple roles of the PI3K/PKB (Akt) pathway in cell cycle progression. Cell Cycle 2: 339-345, 2003.

64. Olive PL: Detection of DNA damage in individual cells by analysis of histone H2AX phosphorylation. Methods Cell Biol 75: 355-373, 2004

65. Nowak E, Etienne O, Millet P, et al: Radiation-induced H2AX phosphorylation and neural precursor apoptosis in the developing brain of mice. Radiat Res 165: 155-164, 2006

66. Rogakou EP, Pilch DR, Orr AH, Ivanova VS and Bonner WM: DNA double-stranded breaks induce histone H2AX phosphorylation on serine 139. J Biol Chem 273: 5858-5868, 1998.

67. Fernandez-Capetillo O, Lee A, Nussenzweig $M$ and Nussenzweig A: H2AX: the histone guardian of the genome. DNA Repair 3: 959-967, 2004.

68. Stiff T, O'Driscoll M, Rief N, Iwabuchi K, Lobrich M and Jeggo PA: ATM and DNA-PK function redundantly to phosphorylate $\mathrm{H} 2 \mathrm{AX}$ after exposure to ionizing radiation. Cancer Res 64: 2390-2396, 2004

69. Hiraga S, Ohnishi T, Izumoto S, et al: Telomerase activity and alterations in telomere length in human brain tumors. Cancer Res 58: 2117-2125, 1998.

70. Tchirkov A, Rolhion C, Kemeny JL, et al: Clinical implications of quantitative real-time RT-PCR analysis of hTERT gene expression in human gliomas. Br J Cancer 88: 516-520, 2003.

71. Shervington A, Patel R, Lu C, et al: Telomerase subunits expression variation between biopsy samples and cell lines derived from malignant glioma. Brain Res 1134: 45-52, 2007.

72. Hirao T, Urata Y, Kageyama K, et al: Dehydroepiandrosterone augments sensitivity to gamma-ray irradiation in human $\mathrm{H} 4$ neuroglioma cells through down-regulation of Akt signaling. Free Radic Res 42: 957-965, 2008.

73. Ramaswamy S, Nakamura N, Vazquez F, et al: Regulation of G1 progression by the PTEN tumor suppressor protein is linked to inhibition of the phosphatidylinositol 3-kinase/Akt pathway. Proc Natl Acad Sci USA 96: 2110-2115, 1999. 
74. Gottschalk AR, Basila D, Wong M, et al: $\mathrm{p} 27^{\mathrm{Kip} 1}$ is required for PTEN-induced G1 growth arrest. Cancer Res 61: 2105-2111, 2001.

75. Liang J, Zubovitz J, Petrocelli T, et al: PKB/Akt phosphorylates p27, impairs nuclear import of p27 and opposes p27-mediated G1 arrest. Nat Med 8: 1153-1160, 2002.

76. Rosenzweig KE, Youmell MB, Palayoor ST and Price BD: Radiosensitization of human tumor cells by the phosphatidylinositol3-kinase inhibitors wortmannin and LY294002 correlates with inhibition of DNA-dependent protein kinase and prolonged G2-M delay. Clin Cancer Res 3: 1149-1156, 1997.

77. Park JK, Jung HY, Park SH, et al: Combination of PTEN and gamma-ionizing radiation enhances cell death and $\mathrm{G}(2) / \mathrm{M}$ arrest through regulation of AKT activity and p21 induction in nonsmall-cell lung cancer cells. Int J Radiat Oncol Biol Phys 70: 1552-1560, 2008.

78. Toulany M, Kehlbach R, Florczak U, et al: Targeting of AKT1 enhances radiation toxicity of human tumor cells by inhibiting DNA-PKcs-dependent DNA double-strand break repair. Mol Cancer Ther 7: 1772-1781, 2008.

79. Shtivelman E, Sussman J and Stokoe D: A role for PI 3-kinase and PKB activity in the G2/M phase of the cell cycle. Curr Biol 12: 919-924, 2002

80. Lee SR, Park JH, Park EK, Chung CH, Kang SS and Bang OS: Akt-induced promotion of cell-cycle progression at G2/M phase involves upregulation of NF-Y binding activity in PC12 cells J Cell Physiol 205: 270-277, 2005.

81. He L, Yang X, Cao X, Liu F, Quan M and Cao J: Casticin induces growth suppression and cell cycle arrest through activation of FOXO3a in hepatocellular carcinoma. Oncol Rep 29: 103-108, 2013.
82. Chung J, Khadka P and Chung IK: Nuclear import of hTERT requires a bipartite nuclear localization signal and Akt-mediated phosphorylation. J Cell Sci 125: 2684-2697, 2012.

83. Neuhof D, Zwicker F, Kuepper JH, Debus J and Weber KJ: Activation of telomerase by ionizing radiation: differential response to the inhibition of DNA double-strand break repair by abrogation of poly (ADP-ribosyl)ation, by LY294002, or by Wortmannin. Int J Radiat Oncol Biol Phys 69: 887-894, 2007.

84. Fu W, Begley JG, Killen MW and Mattson MP: Anti-apoptotic role of telomerase in pheochromocytoma cells. J Biol Chem 274 7264-7271, 1999.

85. Blackburn EH: Switching and signaling at the telomere. Cell 106: 661-673, 2001.

86. Akiyama M, Yamada O, Kanda N, et al: Telomerase overexpression in K562 leukemia cells protects against apoptosis by serum deprivation and double-stranded DNA break inducing agents, but not against DNA synthesis inhibitors. Cancer Lett 178: 187-197, 2002.

87. Masutomi K, Possemato R, Wong JM, et al: The telomerase reverse transcriptase regulates chromatin state and DNA damage responses. Proc Natl Acad Sci USA 102: 8222-8227, 2005.

88. Ferrandon S, Saultier P, Carras J, et al: Telomere profiling: toward glioblastoma personalized medicine. Mol Neurobiol 47: 64-76, 2013. 